\title{
Research and Development of Biotechnologies Using Zebrafish and Its Application on Drug Discovery
}

\author{
Yutaka Tamaru ${ }^{1,2,3}$, Hisayoshi Ishikawa ${ }^{1}$, \\ Eriko Avşar-Ban ${ }^{1}$, Hajime Nakatani1,2, \\ Hideo Miyake ${ }^{1,2,3}$ and Shin'ichi Akiyama ${ }^{4}$ \\ ${ }^{1}$ Department of Life Science, Graduate School of Bioresources, \\ ${ }^{2}$ Laboratory of Applied Biotechnology, Venture Business Laboratory, \\ ${ }^{3}$ Department of Bioinformatics, Life Science \\ Research Center, Mie University \\ ${ }^{4}$ Department of Nephrology, Graduate School of \\ Medicine, Nagoya University, \\ Japan
}

\section{Introduction}

The zebrafish, Danio rerio, a small minnow from the Indian subcontinent, was first purchased from pet stores in the 1970s and propagated in the laboratory for its attractive attributes such as year-round breeding, large clutch sizes and transparent embryos ${ }^{1}$. It grew in popularity as an experimental system, and in the 1980s and 1990s, a critical mass of researchers began to develop the tools necessary to perform large-scale genetic screens and genomic analyses. Since then, the zebrafish research community has grown to include thousands of researchers, trained largely in the fields of developmental genetics and, more recently, functional genomics. The primary goal of the work carried out by these researchers is to use zebrafish to define the genetic mechanisms underlying vertebrate development, in many cases with direct application to human health. Now, zebrafish has several features that make them an ideal vertebrate model, for example their small size, the ease of breeding, short generation intervals, the embryos are transparent and their early development is wellcharacterized $^{2-6}$. Moreover, zebrafish has recently been successfully incorporated into largescale genetic screens due to the optical clarity of the embryos and their accessibility to various experimental techniques throughout development. The attractiveness of the zebrafish as a model organism is enhanced by the biological availability of continuously improving genomic tools and methodologies for functional characterization of the genes. In addition, transparent zebrafish embryos are well suited to manipulations involving DNA or mRNA injection, cell labeling, and transplantation. Once the scheduled zebrafish genome project is complete, targeted genetic manipulations in zebrafish would be able to become even more desirable. Since adult zebrafish only grow up to $30-50 \mathrm{~mm}$ in length, they can be kept a lot of population in relatively small spaces. Moreover, zebrafish are easy to maintain 
and breed under laboratory conditions, they have short generation times (about 3 months) and can reproduce for about 1.5 years. A number of embryos can be obtained at one time, because female fish easily lay 100-200 eggs in each spawning. After the eggs are fertilized among a pair of zebrafish, the embryos develop rapidly and the formation of somatic structures is achieved within 2-3 days of post-fertilization (Figure 1).

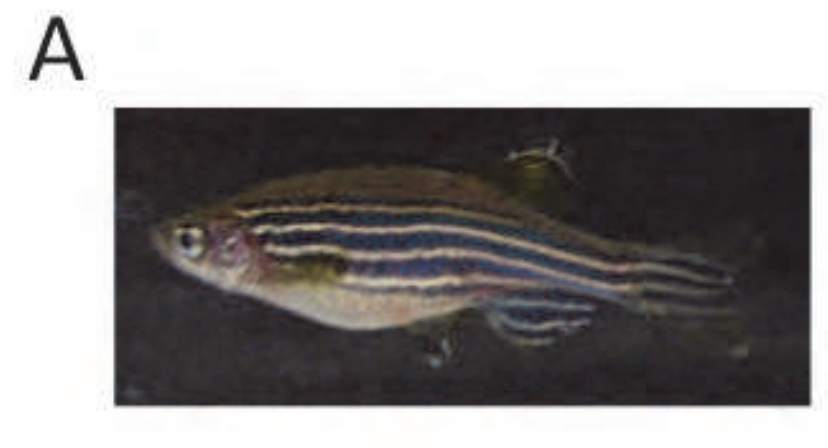

B

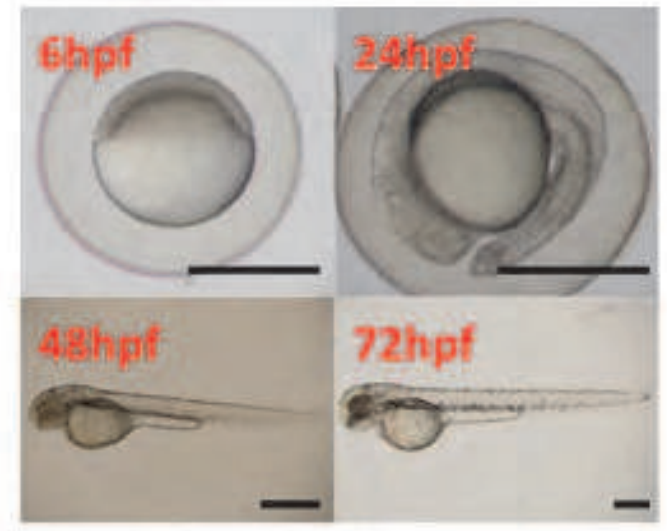

Photo images: female adult zebrafish (A) and zebrafish embryos (B) at 6, 24, 48 and $72 \mathrm{hpf}$, respectively. Scale bar, $500 \mu \mathrm{m}$.

Fig. 1. Zebrafish and its embryogenesis

Forward genetics has been applied, successfully, using methods for large-scale mutagenesis and screening for altered phenotypes, resulting in the discovery of more than 2000 mutations that perturb the normal development of zebrafish ${ }^{7-9}$. In addition to these advantages, their embryonic developmental processes are easily observed in live because of transparent embryos. Methods for standard (non-targeting) germline transgenesis of zebrafish are established ${ }^{10,11}$, with several modifications for increasing their efficiency also reported ${ }^{12-16}$. One advantage of zebrafish transgenics having compared with the mammalian counterpart technology is that reproduction involves external fertilization and embryo development, eliminating the need for surgical intervention. Nowadays, the zebrafish are 
becoming a useful genetic model and starting to be employed in various researches such as infection desiease ${ }^{17}$, cancer research ${ }^{18}$, chemical genetic screening ${ }^{19}$, toxicology ${ }^{20}$, and proteome 21 . Some researchers noted on zebrafish as an in vivo protein expression system, which can be applied for useful protein production 22 , while they used for genetic model are spreading.

\section{Omics research in zebrafish}

Modern biomedical research greatly benefits from large-scale genome-sequencing projects ranging from studies of viruses, bacteria, and yeast to multicellular organisms. There are currently many organisms whose genomes are undergoing systematic sequencing by the next-generation sequencer. The zebrafish genome-sequencing project has been started in 2001 at the Sanger Institute, and all the genome sequence will become available near the future. Zebrafish microarrays have been produced that contain either DNA fragments derived from expressed sequence tag (EST) and cDNA libraries ${ }^{23}$, or from oligonucleotide libraries based on all the genes or transcriptional units predicted from bioinformatic analysis of the entire zebrafish genome. At present, 14,000-22,000 zebrafish genes are included on commercially available arrays (Agilent, Affymetrix, Compugen/Sigma-Aldrich, MWGBiotech and Qiagen/Operon) offering a standardized toolset for zebrafish transcriptional profiling. Recently, microRNA expression profiles have been characterized 24 adding this new family of control factors for gene expression to the zebrafish toolbox repertoire.

An important challenge facing life sciences is to quantitatively describe the bewildering complexity of living organisms ${ }^{25}$, both to appreciate the elegance of nature and to make medically relevant predictions. Indeed, the scope of this complexity is vast. Even the function of a single mammalian cell typically involves coordinated activities among over 20,000 genes, 100,000 proteins ${ }^{26}$, and thousands of small-molecule lipids, carbohydrates and metabolites, each of which may be expressed at differing levels over time. These components interact in physical complexes and functional modules that operate at many levels of organization ${ }^{25}$. On the other hand, the classic method for reverse engineering a system is to poke a component with a stick and then to characterize the effect of the perturbation ${ }^{26}$. An alternative is to poke many components simultaneously and at random, repeating the experiment over many random sets of components 27 . Conveniently, the genetic variation that occurs naturally within a population is a source of multifactorial perturbation 28,29 . The use of natural genetic variation to probe the causal network that links genotype and phenotype has grown recently as large data sets have been generated for many experimental model species, crops and humans ${ }^{30-32}$.

Activity-based profiling (ABP) of proteomes is a powerful strategy for identifying the functional participants in complex biological processes ${ }^{33}$. The recent development of ABP, in which a chemical probe can be used to label and isolate an enzyme from a complex mixture, provides associated with a particular biological activity, thereby taking a step toward their functional identification 34,35 . Moreover, although transcriptional profiling assesses changes in the amount of RNA transcripts in response to a perturbation in environment of an organism, organ, or cell ${ }^{36}$, the abundance of the encoded protein cannot be predicted from the abundance of the transcript. Chromatographic, electrophoretic, and mass spectroscopic methods have also been developed to separate and quantify the amount of individual 
proteins in proteomes ${ }^{37}$. However, the absolute amount of a protein is also, at best, an indirect indicator of its function. The biological potency and activity of a protein cannot be predicted from its abundance; posttranslational modification (phosphorylation, acetylation, or glycosylation) often is the switch for turning the biological activity of a protein on or off. Therefore, protein microarray provides a new strategy for assessing the in vitro interactions of selected members if a proteome with selected ligands 38 . Yet this approach is limited by the availability of relevant proteins and ligands. The zebrafish is also suitable for chemical genomics, in part as a result of the permeability of its embryos to small molecules and consequent avoidance of external confounding maternal effects ${ }^{39}$. The use of zebrafish in high-throughput (HTP) screens of small molecules may allow time-series analyses that could be particularly useful for studying variable gene expression in early development and for toxicogenomic studies. On the other hand, genetic suppressor screens may identify second-site mutations that modify the effect of an existing genetic mutation ${ }^{40}$. In this case, zebrafish larvae are most commonly used for whole-organism screens. Adult zebrafish are popular, too, but their mobility and larger size make them less convenient to use. Embryos develop quickly: within three days of fertilization a zebrafish has a vascular system, a beating heart, the fish equivalent of a pancreas and kidneys. Even better, the larvae, as well as some mutant adult strains, are transparent, facilitating imaging4.

Metabolomics is an emerging tool that can be used to gain insights into cellular and physiological responses. In principle, the metabolome, particularly the unbiased metabolome, would be more diverse and dynamic in terms of chemical and physical properties of metabolites than the transcriptome and proteome. Therefore, the analysis of the metabolome would be suitable for describing the dynamic changes that occur during embryogenesis. However, there have been no reports on the practical application of metabolomics for determining the mechanisms underlying specific biological processes in higher organisms. Therefore, early embryogenesis was a suitable period for determining whether metabolomics can be used to understand complex biological processes. We first identified and profiled 63 types of metabolites from 24 developmental stages, i.e., from 1-cell stage to $48 \mathrm{~h}$ postfertilization (hpf), of zebrafish embryos by using gas chromatography/mass spectrometry (GC/MS) method ${ }^{42}$. Analysis of the GC/MS data with partial least square (PLS) regression clearly indicated a good correlation between metabolomes and developmental stages. Next, we developed a model for predicting embryonic stages on the basis of the metabolome. Thus, zebrafish model is a practical tool to analyze the biological processes in early development.

\section{Studies on activity-based profiling with disease-associated proteins using zebrafish}

Proteomic technology can be very useful in development of production processes for therapeutic proteins by use of genetically engineered animal cells $s^{43,44}$ or human stem cells ${ }^{45}$. However, the analysis of proteomes is significantly more challenging that of genomes. In particular, there is greater diversity in proteins at the amino acid composition level; the proteome is dynamic, both spatially and temporally; and a wide range of variation of protein concentrations exists within cells ${ }^{46}$. Moreover, proteomic analysis is substrate limited, because methods for protein amplification are not available. Therefore, two main areas of this field are 'profiling' and 'functional' proteomics. Profiling proteomics 
encompasses the description of the whole proteome of an organism (by analogy with the genome) and includes organelle mapping and differential measurement of expression levels between cells or conditions. Functional proteomics characterizes protein activity, interactions and the presence of posttranslational modifications.

We are focusing on posttranslational modifications in our laboratory and have recently reported protein O-mannosyltransferases (POMTs) in zebrafish ${ }^{47}$. POMTs (POMT1 and POMT2) catalyze the first step in $O$-mannosyl glycan synthesis 48 , and defects in human POMT1 (hPOMT1) or hPOMT2 result in Walker-Warburg syndrome (WWS), an autosomal recessive disorder associated with severe congenital muscular dystrophy, abnormal neuronal migration and eye anomalies ${ }^{49,50}$. Although zebrafish are superior for vertebrates or human in vivo model, the mice are the most commonly employed vertebrate's model. However, with their advantages of easy manipulation under laboratory conditions, availability of genome information, and the easy establishment of transgenic fish, the zebrafish is gradually spreading into a wide variety of studies as a handier model animal than mouse. In this study, injection of antisense morpholino oligonucleotides of zebrafish POMT1 (zPOMT1) and zPOMT2 resulted in several severe phenotypes including bended body, edematous pericaridium and abnormal eye pigmentation. Immunohistochemistry using anti-glycosylated a-dystroglycan antibody (IIH6) and morphological analysis revealed that the phenotypes of zPOMT2 knockdown were more severe than those of zPOMT1 knockdown, even though the IIH6 reactivity was lost in both zPOMT1 and zPOMT2 morphants. On the other hand, only when both zPOMT1 and zPOMT2 were expressed in human embryonic kidney 293T cells, high levels of protein Omannosyltransferase activity were detected, indicating that both zPOMT1 and zPOMT2 were required for full enzymatic activity. Moreover, either heterologous combination, zPOMT1 and hPOMT2 or hPOMT1 and zPOMT2, resulted in enzymatic activity in cultured cells. These results indicate that the protein $O$-mannosyltransferase machinery in zebrafish and humans is conserved and suggest that zebrafish may be useful for functional studies of protein $O$-mannosylation. More recently, Dr. Kunkel's group has reported that two known zebrafish dystrophin mutants, sapje and sapje-like (sapc/100), represent excellent smallanimal models of human muscular dystrophy ${ }^{51}$. Using these dystrophin-null zebrafish, they have screened the Prestwick chemical library for small molecules that modulate the muscle phenotype in these fish. With a quick and easy birefringence assay, they have identified seven small molecules that influence muscle pathology in dystrophin-null zebrafish without restoration of dystrophin expression. Finally, three of seven candidate chemicals restored normal birefringence and increased survival of dystrophin-null fish.

\section{Recent genetic engineering in zebrafish}

The transgenic fish technology is employed in diverse areas of biological researches including analysis of regulatory elements, gene over-expression, tracing of cellular lineages, mutagenesis and protein analysis. The method of gene transfer into vertebrate embryos is commonly performed by microinjection into embryo at the one cell stage. However, in the most of the mammalian's cases, it is generally difficult to obtain the embryos at quite early stage, and more difficult to maintain externally those isolated embryos. In the case of zebrafish, a huge number of embryos at one cell stage are easily available at one time because eggs are external-fertilized and spawned hundreds of eggs weekly. In general, 
microinjection into zebrafish embryos is relatively easier than that of other fish because of their soft chorion. Therefore, it is easy to imagine that a large numbers of injections will be needed for developing protein expression in zebrafish. To improve performance of injection by hand, we are developing auto-injection machine for zebrafish eggs (Figure 2). This injection system can currently operate 100 pL per embryo level injection, and the injectioin speed is 20 eggs per minute.

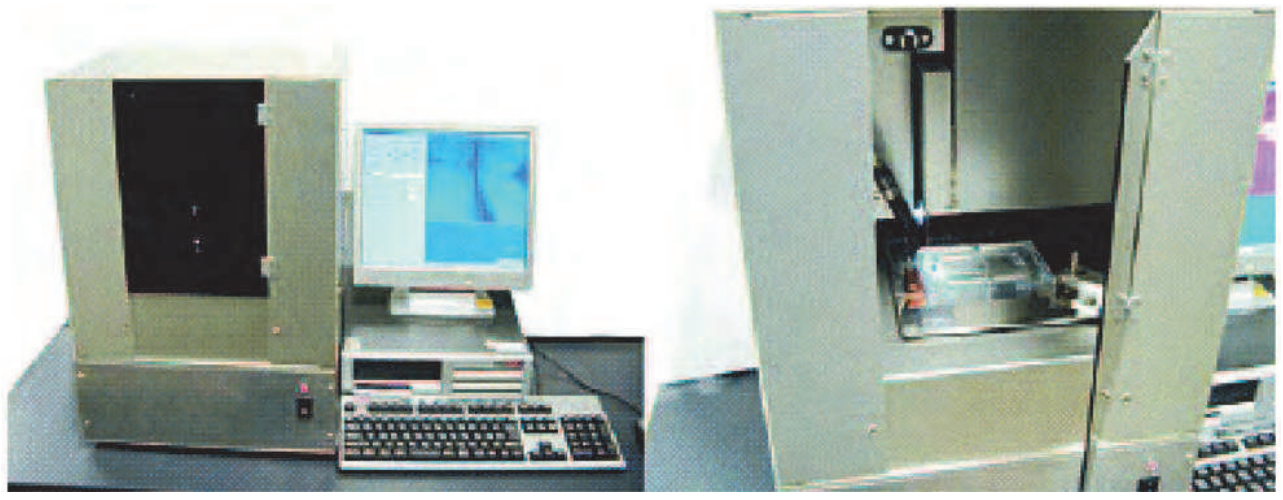

Fig. 2. Fully automated injection system for zebrafish

Techniques for reverse genetic approaches in zebrafish are limited to mRNA knockdown strategies using modified antisense oligomers (morpholinos) 52 and TILLING for point mutations by detection of heterozygosity in a locus of interest, and subsequent sequencing, among a library of chemically mutagenized gametes. On the other hand, conventional gene targeting, a powerful technique for gene disruption in mouse embryonic stem cells ${ }^{53}$, often requires positive-negative selection with cytotoxic drugs ${ }^{54}$, which is inapplicable in the context of a vertebrate embryo. In 2008, the use of zinc-finger nucleases (ZFNs) for somatic and germline disruption of genes in zebrafish, in which targeted mutagenesis was previously intractable, have been repoted 55,56 . ZFNs induce a targeted double-strand break in the genome that is repaired to generate small insertions and deletions. Therefore, only coinjection of mRNAs encoding these ZFNs into one-cell-stage zebrafish embryos led to mutagenic lesions at the target site that were transmitted through the germ line with high frequency. In near future, the use of engineered ZFNs to introduce heritable mutations into a genome obviates the need for embryonic stem cell lines and should be applicable to most animal species for which early stage embryos are easily accessible.

\section{Development of protein expression vectors in zebrafish}

The plasmid DNA has been used for expression of exogenous gene in wide variety of animals. For the zebrafish, the pXeX vector might be first used for protein expression in zebrafish, which is originally used for protein expression in Xenopus embryo ${ }^{57}$, containing the transcription regulatory regions of the Xenopus laevis elongation factor-1 alpha gene (EF1 alpha) and SV40 polyadenilation signaling. Amsterdam et al. cloned green fluorescent 
protein (GFP) into pXeX vector (pXeX-GFP) and expressed GFP in zebrafish embryos by plasmid injection into fertilized eggs ${ }^{58}$. Moreover, they constructed $\mathrm{pXIG}$ vector which is originally constructed for expression in zebrafish embryos, based on the backbone of $\mathrm{pXeX}$ vector. They inserted rabbit beta-globin IVS2 into the promoter region of $\mathrm{pXeX}$ vector, and then followed by GFP's open reading frame. Using the pXIG vector, they expressed GFP in the whole body of transgenic zebrafish and observed more frequent generation of transgenic fish than that of pXeX-GFP injectant.
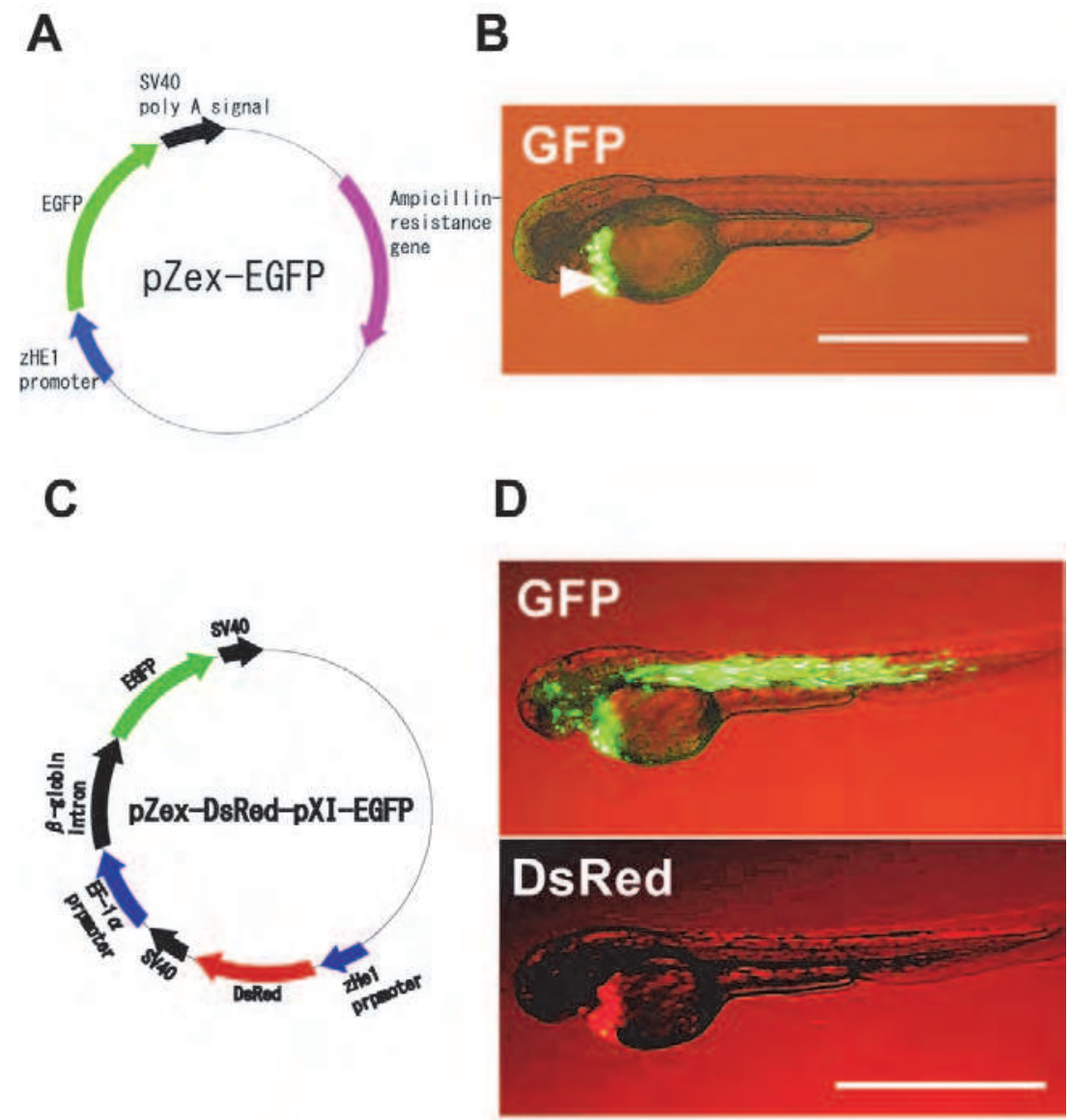

The pZex-EGFP vector (A) or pZex-DsRed-pXI-EGFP tandem vector (C) was injected into zebrafish embryos and pZex-EGFP expression in hatching gland at $48 \mathrm{hpf}$ (arrow head in B) or pZex-DsRed-pXIEGFP expression in zebrafish Embryos at $48 \mathrm{hpf}$ (D) was observed. Note that expression of GFP in panel $\mathrm{D}$ is ubiquitous, while the expression of DsRed was limited in hatching gland cells. Scale bars, $500 \mu \mathrm{m}$.

Fig. 3. Protein expression vectors and their expression in zebrafish embryos 
We constructed the pZex vector derived from the pXI vector in our laboratory (Figure 3A). This vector included the promoter region of zebrafish he1 (hatching enzyme 1) gene and GFP is expressed in hatching gland cells during only early developmental stages up to 72 hrs post-fertilization (hpf) (Figure 3B). Furthermore, since tissue-specific and stage-specific protein expression by pZex can be possible in zebrafish embryos, even some apoptosisrelated protein is able to express. Although one of the critical problems for protein expression in zebrafish embryos is expression efficiency, most target proteins were easily expressed by pZex in more than $30 \%$ of injected embryos. Furthermore, we constructed a pXI-EGFP-pZex-DsRed vector tandemly connected with both pXI-EGFP and pZex-DsRed, (Figure 3C). EGFP and DsRed can be successfully expressed in each promoter-dependent manner (Figure 3D). These constructs can be applied for the identification of embryos expressing target proteins. Thus, we can choose efficiently the embryos expressing the target protein only observed by monitoring fluorescence.

\section{Zebrafish as a model for combinatorial bioengineering}

In recent years, the importance of the target proteins with therapeutic potential and drug discovery is getting more and more increasing. For example, several monoclonal antibodies have already applied to human cancer therapy because of their minimum side effects and specificity to the target disease. For the purpose of developing the novel molecular target drugs, the spatiotemporal protein-protein interactions in normal or abnormal tissue has been attempted to analyze extensively. In addition, the effective production of such a functional mammalian protein in large scale and at low cost will be also demanded as spreading the use of these proteins in human therapy or researches like protein structure analysis for novel drug discovery.

Although expression and preparation of target proteins in large scale has been tried in bacterial cells, bacterial recombinant proteins often lost their native properties. It is due to the differences of protein synthesis system between eukaryotic cells and prokaryotic cells. That is, protein synthesis on endoplasmic reticulum (ER) follows by various posttranslational modifications such as glycosylation, phosphorylation, and N-terminus conjugation of several lipids in eukaryotic cells. Accordingly, such posttranslational modifications never occur in prokaryotic cells. On the other hand, the posttranslational modifications are often critical for the correct folding or functions of mammalian proteins. For this reason, the mammalian proteins for pharmaceutical agent or protein structure analysis has been produced by eukaryotic cells or extracted from mammalian tissues. However, these methods are not efficient and often less expensive. Therefore, several alternative ways to produce mammalian proteins more efficient than using cell cultures has been studied and one successful example are to secrete the protein in the milk of transgenic mammals, like a pig59,60. However, maintenance of such a large mammal needs large spaces and high cost. In addition, it is originally unable to produce and keep various kinds of transgenic mammals.

The zebrafish are easy to maintain large population in a small space, lay thousands of eggs weekly, and can generate and reproduce transgenic fishes easily. Therefore, we introduced and described the advantage of zebrafish researches. In order to apply this tool to combinatorial bioengineering in the post-genomic era, we attempt to use the ability and 


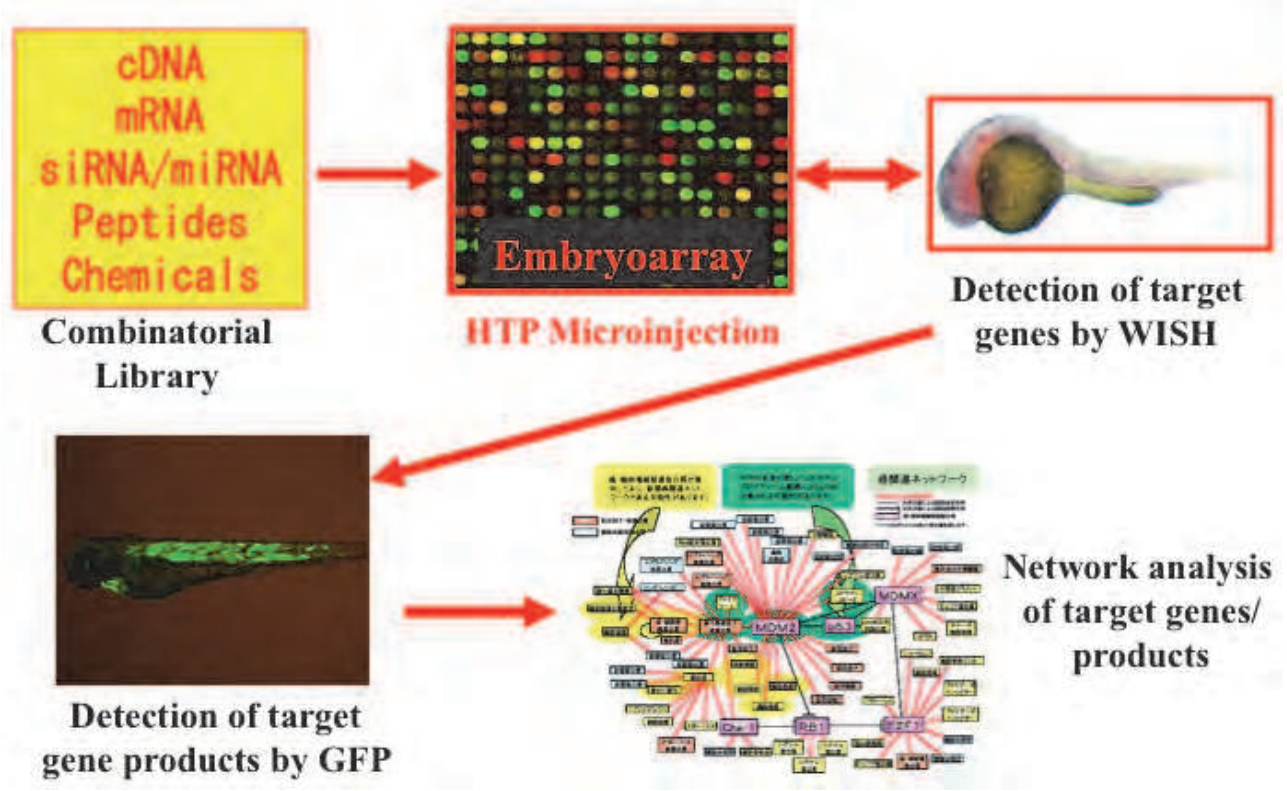

Fig. 4. Scheme of combinatorial bioengineering using zebrafish embryogenesis

potentiality of zebrafish "embryoarray" as protein sources (Figure 4). In fact, there are many and various kinds of libraries for not only genes but also natural or artificial compounds. For instance, if complete cDNAs encoding a total of human genes were able to transfer into the zebrafish, human protein library would be obtained and could be stably expressed in all generations of transgenic zebrafish with their native properties. Thus, we believe that transgenic zebrafish have brought us remarkable advances in many areas of biological researches. Therefore, we would like to emphasize the additional advantages that the target proteins expressed in zebrafish would have a proper conformation, activity and posttranslational modifications. The effective production of such functional mammalian proteins will become gradually important as increasing attention to developing pharmaceutical proteins.

\section{Zebrafish and its potential application on drug discovery}

The low-cost and high clutch-size zebrafish is, at the embryonal and larval stages, optically transparent, permitting visualization of pathogens and lesions in real time ${ }^{61}$, as well as offering exciting possibilities for high-throughput imaging 62 . Zebrafish are also amenable to forward genetic screening, or reverse genetics techniques such as injection of morpholinos (inhibitory of mRNA translation) ${ }^{63,64}$. More recently, it is clear that much can be learned about Tuberculosis (TB) from the study of Mycobacterium marinum infections in zebrafish, and the use of this pathogen offers practical advantages when compared to M. tuberculosis, such as lower biosafety restrictions and faster growth rate ${ }^{65}$. That notwithstanding, it was of interest to study 
the human pathogen, M. tuberculosis, directly in zebrafish via robotic injection system. Importantly, they use reference compounds to validate their system in the testing of molecules that prevent tuberculosis progression, making it highly suited for investigating novel antituberculosis compounds in vivo. Thus, by introducing advanced biotechnologies into zebrafish, we are confident that our approach will contribute to the novel knowledge of drug discovery and could be helpful for the development of new medicines.

\section{Acknowledgements}

This work was supported by grants from the Wakayama Prefecture Collaboration of Regional Entities for the Advancement of Technological Excellence (Y.T) and SENTAN (Y.T), Japan Science and the Technology Agency and the New Energy and Industrial Technology Development Organization (02A09003d) (Y.T).

\section{References}

[1] Schilling TF, Webb J. Considering the zebrafish in a comparative context. J Exp Zool 2007; 308B: 515-522.

[2] Alestrom P, Holter JL, Nourizadeh-Lillabadi R. Zebrafish in functional genomics and aquatic biomedicine. Trends Biotechnol 2006; 24: 15-21.

[3] Streisinger G, Walker C, Dower N, Knauber D, Singer F. Production of clones of homozygous diploid zebra fish (Brachydanio rerio). Nature 1981; 291: 293-296.

[4] Kimmel CB. Genetics and early development of zebrafish. Trends Genet 1989; 5: 283-288.

[5] Nusslein-Volhard C. Of flies and fishes. Science 1994; 266: 572-574.

[6] Sprague J, Clements D, Conlin T, Edwards P, Frazer K, Schaper K, Segerdell E, Song P, Sprunger B, Westerfield $M$. The zebrafish information network (ZFIN): the zebrafish model organism database. Nucleic Acids Res 2003; 31(1): 241-243.

[7] Currie PD. Zebrafish genetics: mutant cornucopia. Curr Biol 1996; 6: 1548-1552.

[8] Holder N, McMahon A. Genes from zebrafish. Nature 1996; 384: 515-516.

[9] van Eeden FJ, Granato M, Odenthal J, Haffter P. Developmental mutant screens in the zebrafish. Methods Cell Biol 1999; 60: 21-41.

[10] Stuart GW, McMurray JV, Westerfield M. Replication, integration and stable germline transmission of foreign sequences injected into early zebrafish embryos. Development 1988; 103 (2): 403-412.

[11] Collas P, Aleström P. Nuclear localization signals: a driving force for nuclear transport of plasmid DNA in zebrafish. Biochem Cell Biol 1997; 75 (5): 633-640.

[12] Collas P, Alestrom P. Nuclear localization signals enhance germline transmission of a transgene in zebrafish. Transgenic Res 1998; 7: 303-309.

[13] Liang MR, Aleström P, Collas P. Glowing zebrafish: single luciferase transgene integration, transmission and expression promoted by nuclear localization signals. Mol Reprod Dev 2000; 55 (1): 8-13.

[14] Thermes V, Grabher C, Ristoratore F, Bourrat F, Choulika A, Wittbrodt J, Joly JS. I-SceI meganuclease mediates highly efficient transgenesis in fish. Mech Dev 2002; 118 (1-2): 91-98. 
[15] Davidson AE, Balciunas D, Mohn D, Shaffer J, Hermanson S, Sivasubbu S, Cliff MP, Hackett PB, Ekker SC. Efficient gene delivery and gene expression in zebrafish using the Sleeping Beauty transposon. Dev Biol 2003;263(2):191-202.

[16] Shin J, Park HC, Topczewska JM, Mawdsley DJ, Appel B. Netural cell fate analysis in zebrafish using olig2 BAC transgenics. Methods Cell Sci 2003; 25 (1-2): 7-14.

[17] Carvalho R, de Sonneville J, Stockhammer OW, Savage ND, Veneman WJ, Ottenhoff TH, Dirks RP, Meijer AH, Spaink HP. A high-throughput screen for tuberculosis progression. PLoS One. 2011; 6 (2): e16779.

[18] White RM, Cech J, Ratanasirintrawoot S, Lin CY, Rahl PB, Burke CJ, Langdon E, Tomlinson ML, Mosher J, Kaufman C, Chen F, Long HK, Kramer M, Datta S, Neuberg D, Granter S, Young RA, Morrison S, Wheeler GN, Zon LI. DHODH modulates transcriptional elongation in the neural crest and melanoma. Nature 2011; 471 (7339): 518-522.

[19] Kaufman CK, White RM, Zon L. Chemical genetic screening in the zebrafish embryo. Nat Protoc. 2009; 4 (10): 1422-1432.

[20] Weigta S, Hueblera N, Streckerb R, Braunbeckb T, Broscharda TH. Zebrafish (Danio rerio) embryos as a model for testing proteratogens. Toxicology 2011;281:2536.

[21] Link V, Shevchenko A, Heisenberg CP. Proteomics of early zebrafish embryos. BMC Develop Biol 2006;6:1.

[22] Hwang G., Müller M, Rahman, Darren W. Williams, Paul J, Murdock K, Pasi J, Goldspink G, Farahmand H, Maclean N. Fish as Bioreactors: Transgene Expression of Human Coagulation Factor VII in Fish Embryos. Mar. Biotechnol. 2004; 6: 485492.

[23] Handley-Goldstone HM, Grow MW, Stegeman JJ. Cardiovascular gene expression profiles of dioxin exposure in zebrafish embryos. Toxicol Sci 2005; 85: 683-693.

[24] Wienholds E, Kloosterman WP, Miska E, Alvarez-Saavedra E, Berezikov E, de Bruijn E, Horvitz HR, Kauppinen S, Plasterk RH. MicroRNA expression in zebrafish embryonic development. Science 2005; 309: 310-311.

[25] Stelling J, Sauer U, Szallasi Z, Doyle FJ III, Doyle J. Robustness of cellular functions. Cell 2004;118:675-685.

[26] Koonin EV, Wolf YI, Karev G.P. The structure of the protein universe and genome evolution. Nature 2002; 420: 218-223.

[27] Rockman MV. Reverse engineering the genotype-phenotype map with natural genetic variation. Nature 2008; 456: 738-744.

[28] Jansen RC, Nap JP. Genetical genomics: the added value from segregation. Trends Genet 2001; 17: 388-391.

[29] Jansen RC. Studying complex biological systems using multifactorial perturbation. Nature Rev Genet 2003;4:145-151.

[30] Brem RB, Yvert G, Clinton R, Kruglyak L. Genetic dissection of transcriptional regulation in budding yeast. Science 2002;296:752-755.

[31] Schadt EE, Monks SA, Drake TA, Lusis AJ, Che N, Colinayo V, Ruff TG, Milligan SB, Lamb JR, Cavet G, Linsley PS, Mao M, Stoughton RB, Friend SH. Genetics of gene expression surveyed in maize, mouse and man. Nature 2003; 422: 297-302. 
[32] Rockman MV, Kruglyak L. Genetics of global gene expression. Nature Rev Genet 2006; 7: 862-872 (2006).

[33] Gerlt JA. "Fishing" for the functional proteome. Nat Biotechnol 2002; 20: 786-787.

[34] Cravatt BF, Sorensen EJ. Chemical strategies for the global analysis of protein function. Curr Opin Chem Biol 2000; 4: 663-668.

[35] Greenbaum D, Medzihradszky KF, Burlingame A, Bogyo M. Epoxide electrophiles as activity-dependent cysteine protease profiling and discovery tools. Chem Biol 2000; 7: 569-581.

[36] Schena M, Shalon D, Davis RW, Brown PO. Quantitative monitoring of gene expression patterns with a complementary DNA microarray. Science 1995; 270: 467470 .

[37] Aebersold R, Goodlett DR. Mass spectrometry in proteomics. Chem Rev 2001; 101: 269295.

[38] MacBeath G, Schreiber SL. Printing proteins as microarrays for high-throughput function determination. Science 2000; 289: 1760-1763.

[39] Pichler FB, Laurenson S, Williams LC, Dodd A, Copp BR, Love D. Chemical discovery and global gene expression analysis in zebrafish. Nat Biotechnol 2003; 21: 879-883.

[40] Peterson RT, Shaw SY, Peterson TA, Milan DJ, Zhong TP, Schreiber SL, MacRae CA, Fishman MC. Chemical suppression of a genetic mutation in a zebrafish model of aortic coarctation. Nat Biotechnol 2004; 22: 595-599.

[41] Baker M. Screening: the age of fishes. Nat Meth 2011; 8 (1): 47-51.

[42] Hayashi S, Akiyama S, Tamaru Y, Takeda Y, Fujiwara T, Inoue K, Kobayashi A, Maegawa S, Fukusaki E. A novel application of metabolomics in vertebrate development. Biochem Biophys Res Commun. 2009; 386 (1):268-272.

[43] Gupta P, Lee KH. Genomics and proteomics in process development: Opportunities and challenges. Trends Biotechnol 2007; 25: 324-330.

[44] Al-Fageeh MB, Marchant RJ, Carden M., Smales CM. The cold-shock response in cultured mammalian cells: Harnessing the response for the improvement of recombinant protein production. Biotech Bioeng 2005; 93:829-835.

[45] Li Y, Powell S, Brunette E, Lebkowski J, Mandalam R. Expansion of human embryonic stem cells in defined serum-free medium devoid of animal-derived products. Biotechnol Bioeng 2005; 91: 688-698.

[46] Choudhary J, Grant SGN. Proteomics in postgenomic neuroscince: the end of the beginning. Nat Neurosci 2004; 7: 440-445.

[47] Avsar-Ban E, Ishikawa H, Manya H, Watanabe M, Akiyama S, Miyake H, Endo T, Tamaru Y. Protein O-mannosylation is necessary for normal embryonic development in zebrafish. Glycobiology. 2010; 20 (9): 1089-1102.

[48] Manya H, Chiba A, Yoshida A, Wang X, Chiba Y, Jigami Y, Margolis RU, Endo T. Demonstration of mammalian protein O-mannosyltransferase activity: coexpression of POMT1 and POMT2 required for enzymatic activity. Proc Natl Acad Sci USA 2004; 101 (2): 500-505.

[49] Beltran-Valero de Bernabe D, Currier S, Steinbrecher A, Celli J, van Beusekom E, van der Zwaag B, Kayserili H, Merlini L, Chitayat D, Dobyns WB, Cormand B, Lehesjoki AE, Cruces J, Voit T, Walsh CA, van Bokhoven H, Brunner HG. 
Mutations in the O-mannosyltransferase gene POMT1 give rise to the severe neuronal migration disorder Walker-Warburg syndrome. Am J Hum Genet. 2002; 71 (5): 1033-1043.

[50] van Reeuwijk J, Janssen M, van den Elzen C, Beltran-Valero de Bernabe D, Sabatelli P, Merlini L, Boon M, Sche"er H, Brockington M, Muntoni F, Huynen MA, Verrips A, Walsh CA, Barth PG, Brunner HG, van Bokhoven H. POMT2 mutations cause adystroglycan hypoglycosylation and Walker-Warburg syndrome. J Med Genet. 2005; 42 (12): 907-912.

[51] Kawahara G, Karpf JA, Myers JA, Alexander MS, Guyon JR, Kunkel LM. Drug screening in a zebrafish model of Duchenne muscular dystrophy. Proc Natl Acad Sci USA. 2011; 108 (13): 5331-5336.

[52] Nasevicius A, Ekker SC. Effective targeted gene 'knockdown' in zebrafish. Nat Genet 2000; 26: 216-220.

[53] Thomas KR, Folger KR, Capecchi MR. High frequency targeting of genes to specific sites in the mammalian genome. Cell 1986; 44: 419-428.

[54] Sedivy JM, Joyner AL. Gene Targeting. (Oxford University Press, Oxford, 1992).

[55] Meng X, Noyes MB, Zhu LJ, Lawson ND, Wolfe SA. Targeted gene inactivation in zebrafish using engineered zinc-finger nucleases. Nat Biotechnol 2008; 26:695-701.

[56] Doyon Y, McCammon JM, Miller JC, Faraji F, Ngo C, Katibah GE, Amora R, Hocking TD, Zhang L, Rebar EJ, Gregory PD, Urnov FD, Amacher SL. Heritable targeted gene disruption in zebrafish using designed zinc-finger nucleases. Nat Biotechnol 2008; 26: 702-708.

[57] Johnson AD, Krieg PA. pXeX, a vector for efficient expression of cloned sequences in Xenopus embryos. Gene1994; 147: 223-226.

[58] Amsterdam A, Lin S, Hopkins N. The Aequorea victoria green fluorescent protein can be used as a reporter in live zebrafish embryos. Dev Biol 1995; 171: 123-129.

[59] Paleyanda RK, Velander WH, Lee TK, Scandella DH, Gwazdauskas FC, Knight JW, Hoyer LW, Drohan WN, Lubon H. Transgenic pigs produce functional human factor VIII in milk. Nat Biotechnol 1997; 15: 971-975.

[60] Van Cott KE, Lubon H, Gwazdauskas FC, Knight J, Drohan WN, Velander WH. Recombinant human protein $\mathrm{C}$ expression in the milk of transgenic pigs and the effect on endogenous milk immunoglobulin and transferring levels. Transgenic Res 2001; 10: 43-51.

[61] Lesley R, Ramakrishnan L. Insights into early mycobacterial pathogenesis from the zebrafish. Curr Opin Microbiol 2008; 11 (3): 277-283.

[62] Pardo-Martin C, Chang TY, Koo BK, Gilleland CL, Wasserman SC, Yanik MF. Highthroughput in vivo vertebrate screening. Nat Methods 2010; 7 (8): 634-636.

[63] Amsterdam A, Hopkins N. Mutagenesis strategies in zebrafish for identifying genes involved in development and disease. Trends Genet 2006; 22 (9): 473-478.

[64] Nasevicius A, Ekker SC. Effective targeted gene 'knockdown' in zebrafish. Nat Genet 2000; 26 (2): 216-220. 
[65] Carvalho R, de Sonneville J, Stockhammer OW, Savage ND, Veneman WJ, Ottenhoff TH, Dirks RP, Meijer AH, Spaink HP. A high-throughput screen for tuberculosis progression. PLoS One. 2011; 6 (2): e16779. 


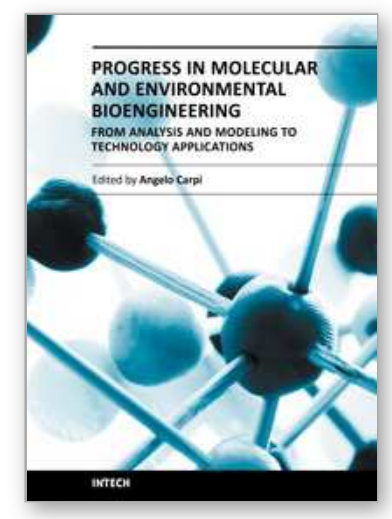

\author{
Progress in Molecular and Environmental Bioengineering - From \\ Analysis and Modeling to Technology Applications \\ Edited by Prof. Angelo Carpi
}

ISBN 978-953-307-268-5

Hard cover, 646 pages

Publisher InTech

Published online 01, August, 2011

Published in print edition August, 2011

This book provides an example of the successful and rapid expansion of bioengineering within the world of the science. It includes a core of studies on bioengineering technology applications so important that their progress is expected to improve both human health and ecosystem. These studies provide an important update on technology and achievements in molecular and cellular engineering as well as in the relatively new field of environmental bioengineering. The book will hopefully attract the interest of not only the bioengineers, researchers or professionals, but also of everyone who appreciates life and environmental sciences.

\title{
How to reference
}

In order to correctly reference this scholarly work, feel free to copy and paste the following:

Yutaka Tamaru, Hisayoshi Ishikawa, Eriko Avşar-Ban, Hajime Nakatani, Hideo Miyake and Shin'ichi Akiyama (2011). Research and Development of Biotechnologies Using Zebrafish and Its Application on Drug Discovery, Progress in Molecular and Environmental Bioengineering - From Analysis and Modeling to Technology Applications, Prof. Angelo Carpi (Ed.), ISBN: 978-953-307-268-5, InTech, Available from:

http://www.intechopen.com/books/progress-in-molecular-and-environmental-bioengineering-from-analysisand-modeling-to-technology-applications/research-and-development-of-biotechnologies-using-zebrafish-andits-application-on-drug-discovery

\section{INTECH}

open science | open minds

\author{
InTech Europe \\ University Campus STeP Ri \\ Slavka Krautzeka 83/A \\ 51000 Rijeka, Croatia \\ Phone: +385 (51) 770447 \\ Fax: +385 (51) 686166 \\ www.intechopen.com
}

\author{
InTech China \\ Unit 405, Office Block, Hotel Equatorial Shanghai \\ No.65, Yan An Road (West), Shanghai, 200040, China \\ 中国上海市延安西路65号上海国际贵都大饭店办公楼405单元 \\ Phone: +86-21-62489820 \\ Fax: +86-21-62489821
}


(C) 2011 The Author(s). Licensee IntechOpen. This chapter is distributed under the terms of the Creative Commons Attribution-NonCommercialShareAlike-3.0 License, which permits use, distribution and reproduction for non-commercial purposes, provided the original is properly cited and derivative works building on this content are distributed under the same license. 